\title{
COMPREHENSIVE TESTS OF SINTERED CARBIDES IN THE ASPECT OF CONICAL PICKS OPERATIONAL LIFE
}

\author{
Wojciech GRZEGORZEK* \\ Marek JASZCZUK
}

Silesian University of Technology, Faculty of Mining, Safety Engineering and Industrial Automation, Akademicka 2, 44-100 Gliwice, Poland

\begin{abstract}
The results of tests on the brittle fracture and abrasive wear of conical picks sintered carbides taking into account the size of tungsten carbide grains and the content of cobalt are presented. The tests were carried out on the innovative laboratory stand for tribological tests using the method for determination of resistance to edge fracture and abrasive wear. Test results have shown that an increase in the size of tungsten carbide grains, and thus an increase in the cobalt content, reduces the wear resistance and increases the resistance to brittle fracture. The results of the tests of sintered carbides inserts in the aspect of their durability are presented.
\end{abstract}

Keywords: conical picks, sintered carbides, fracture and abrasion resistance

\section{INTRODUCTION}

Conical picks, used for example in roadheaders, are subjected to wear during cutting the rocks. The rate of wear depends on rock properties, design of picks, their load resulting from operational parameters of a roadheader and a design of the cutterhead as well as on the picks quality. The rate of picks replacement has an essential impact on the costs of roadway drivage. Besides, wear of the picks causes an increase of specific energy consumption which increases costs and also reduces the machine production rate. From the tests, conducted by R. Mann (2014), it can be concluded that in the case of driving

* Corresponding author: wojciech.grzegorzek@polsl.pl (W. Grzegorzek)

doi: 10.37190/msc202709 
a roadway of the cross-section area $13.3 \mathrm{~m}^{2}$ the specific energy consumption due to wear of cutting picks is doubled (Fig. 1). Shale of compressive strength $R_{c}=56 \mathrm{MPa}$, and sand shale at the bottom $\left(R_{c}=65 \mathrm{MPa}\right)$, was deposited in the near-roof section of the roadway. Coal of compressive strength $R_{c}=16 \mathrm{MPa}$ was found in between. The roadway was developed in 703/1 seam at $900 \mathrm{~m}$ level in the Rydultowy mine. Figure 1 shows the correlation between specific energy consumption during shale cutting and the roadheader efficiency when using new and used conical picks.

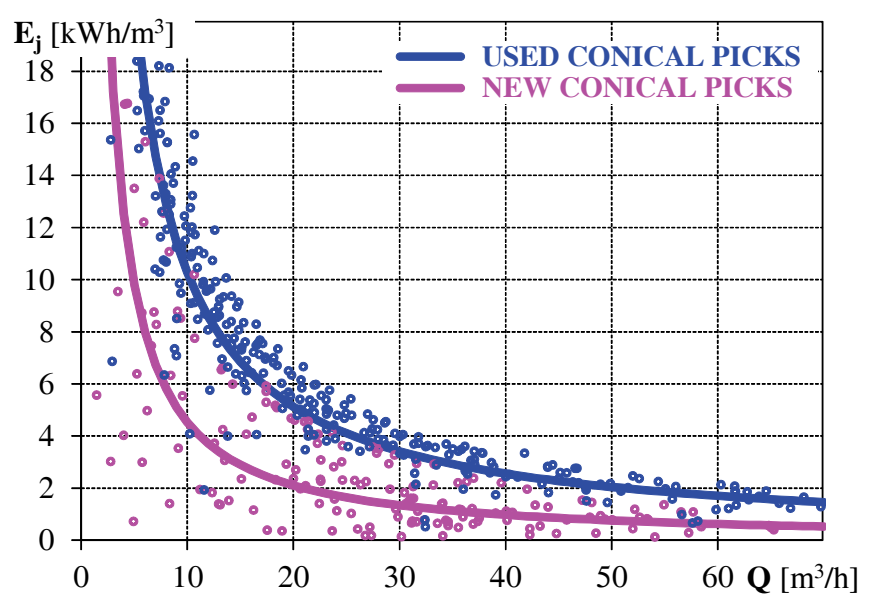

Fig. 1. Correlation between roadheader productivity nd specific energy consumption $E_{j}$ (Mann 2014)

When using new picks, the average cutting efficiency was $26.5 \mathrm{~m}^{3} / \mathrm{h}$, and for used picks $25.3 \mathrm{~m}^{3} / \mathrm{h}$. The average energy consumption for cutting with new picks was $2.01 \mathrm{kWh} / \mathrm{m}^{3}$. In a result of higher load, caused by picks wear, power consumption increased. So, for the similar cutting conditions the mean specific energy consumption rose to $4.22 \mathrm{kWh} / \mathrm{m}^{3}$ (Mann 2014).
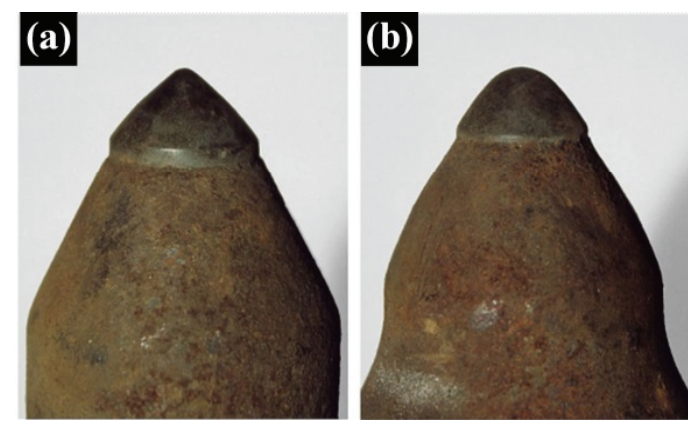

Fig. 2. Symmetric abrasive wear of conical picks 
Analysis of the wear types of conical picks allows to identify their reasons of wear. Most often it is abrasive wear characterized by a change in shape and dimensions of the cutting pick (Fig. 2a, b). Due to the possibility of pick rotation in the pick holder, abrasion of sintered carbides occurs, which causes increase in the tip angle. In consequence, the tip is shortened.

Breaking off the sintered carbides insert (Fig. 3a) or its brittle fracture (Fig. 3b) is another form of wear of the picks. Breaking is usually caused by improper carbide insert embedment in the pick body due to improper filling the solder gap or excessive protrusion of sintered carbides insert from the pick body. Crumbling of the sintered carbides insert is caused by its low resistance to brittle fracture, probably caused by material flaws or incorrect selection of the carbides grade for the cutting conditions.

An analysis of conical picks damages shows that the factors deciding about their operational life include a resistance of the cutting tip to brittle fracture and abrasive wear, and quality of the conical pick insert embedment in the pick body.
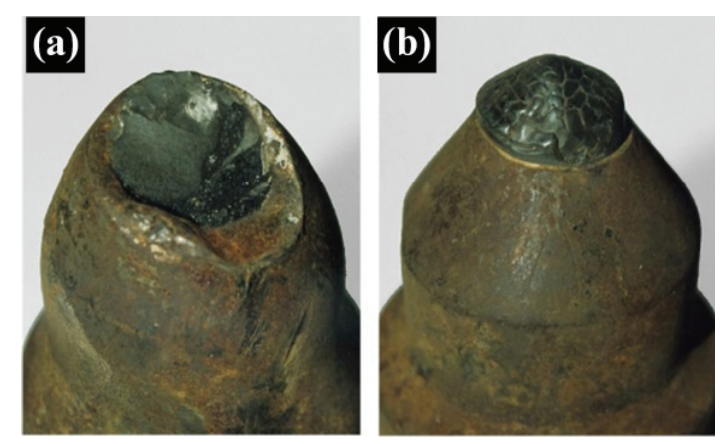

Fig. 3. Spalling and fatigue damages of conical picks

\section{NEW METHOD FOR TESTING THE RESISTANCE TO BRITTLE FRACTURE AND WEAR OF SINTERED CARBIDES}

Commonly used methods for testing, based on the ASTM Standards (ASTM G65-04, 2010) and the instrumentation made by Falex, Tuber Industries, Koehler Instrument or T-07 apparatus take into consideration only the materials abrasive wear (Ścieszka et al. 2015).

In relation to the above it was decided to use a new testing method (Ścieszka et. al., 2013; 2015), in which both the abrasive wear as well as fracture with a comminution of abrasive material occur. It results from the fact that in the tool cutting edge-rock 
contact zone, the mechanical surface and volumetric damages of not only abrasive but also brittle fracture character accumulate.

The abrasion and fracture resistance test of the selected grades of the sintered carbides was carried out on a laboratory stand for testing the structure and tool materials as well as granulated materials. Abrasive wear and fracture are the result of the interaction of hard abradant particles, subjected to forced sliding and rolling on the surface of the tested material samples. As a result of a single or multiple operation of the abradant, a process of micro-cutting, micro-ridging, micro-cracking as well as micro-fatigue takes place. Micro-ridging occurs when a cutting grain or surface unevenness at the moment of movement has a relatively small angle of attack in relation to the mating surface. Micro-cutting occurs, when this angle is relatively large. As the cutting grains are moving, they change their relative position, rotate and begin to ridge. This diversity of wear processes and their conditions results in different combinations of elementary processes, including the destruction and detachment of surface layers.

Friction node is the basic part of the laboratory stand (Fig. 4). A total action of a grainy abrasive material takes place in a cylindrical chamber, where the normal stress $\sigma_{n}$ is controlled by the external force $F_{n}$. The torque on the driving shaft enables to overcome the shear resistance of the abrasive material and of the friction resistance on the contact edge of the sample and abrasive material. A detailed description of the testing procedure is presented in (Ścieszka et. al. 2013).
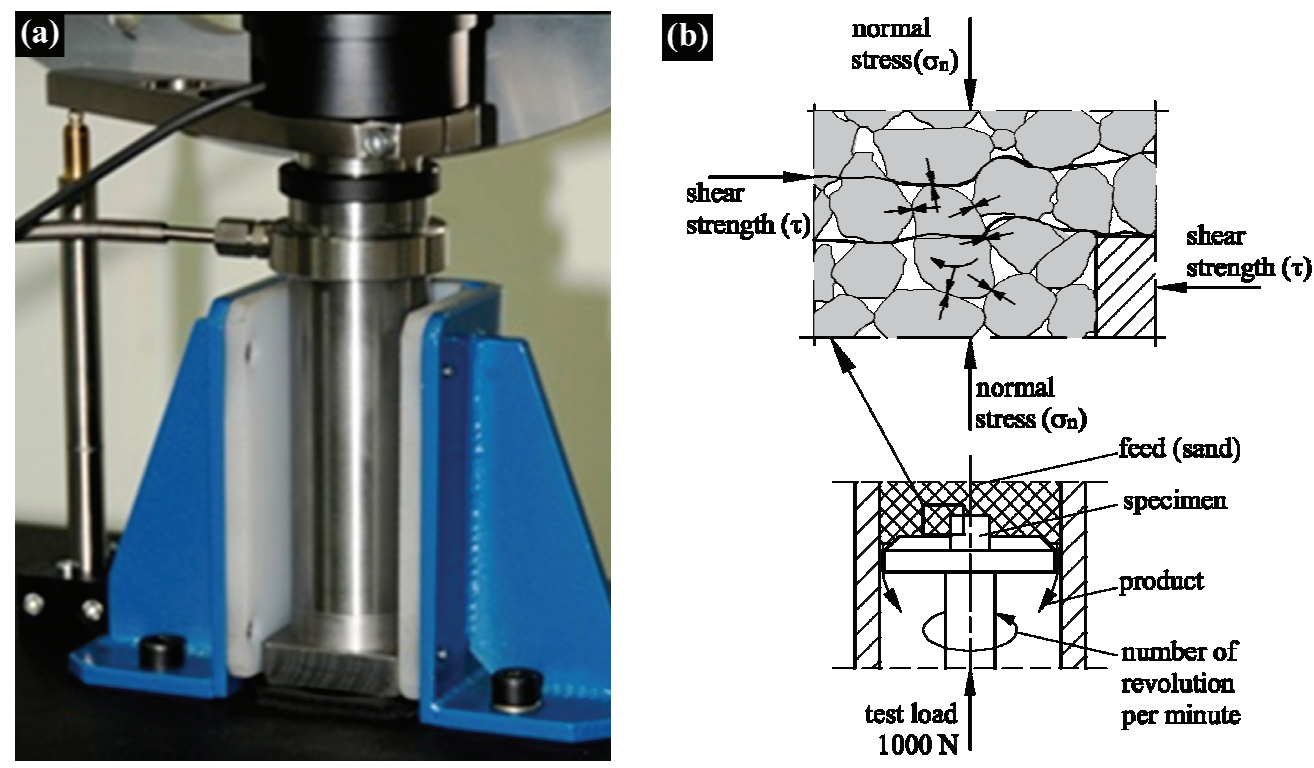

Fig. 4. The view of test stand (a) and schematic diagram of arrangement inside the apparatus and interpretation of interaction between the granular mineral and the bar within shear zone (b) 
The sample had a cuboid shape of a triangle shape base-for the fracture resistance test or of a square base shape - for the abrasion resistance test (Fig. 5). There is also a possibility of testing the materials used for tool blades of conical picks covered with multi-layer anti-wear coating.

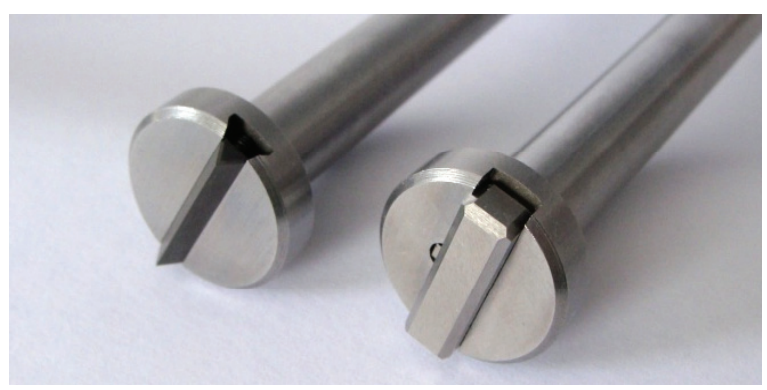

Fig. 5. Photo of the blade samples of triangle cross-section and square cross-section as well as the method of their fixation

The method used for testing the sintered carbides is based on the idea of differentiation between initial tribological transitional processes in which brittle fracture of edges dominates and the stable stage of wearing caused mainly by micro-abrasion mechanism. Testing the stage of wearing enables classifying the sintered carbides regarding their resistance to micro-abrasion. The testing procedure consists of five consecutive tests on one of three edges of the same sample. In each test normal force $F_{n}=1000 \mathrm{~N}$ is used. Other technical parameters are as follows: rotational speed of driving shaft $30 \mathrm{rpm}$, test duration $15 \pm 1$ revolutions, mean sliding distance $666 \pm 44 \mathrm{~mm}$, radius of friction $7.1 \mathrm{~mm}$, active surface of the specimen $72 \mathrm{~mm}^{2}$, abradant - quartz sand $(600-1200 \mu \mathrm{m}) \mathrm{SiO}_{2}$.

Based on the measurement results, the parameters characterizing the brittle breaking and abrasive wear are determined by the Eqs. (1)-(9). Loss of the mass during the first test on a sharp edge of the sample is calculated to determine the resistance to brittle fracture. The results of 4 other tests are used to determine the resistance to abrasive wear. Average mass wear of the sample used for determination of resistance to brittle fracture is calculated from the following relationship:

$$
\Delta \bar{m}_{1}=\frac{1}{n} \sum_{1}^{n} \Delta m_{1}[\mathrm{mg}]
$$

and average mass wear of the sample used to determine the resistance to abrasive wear is described by the following relationship:

$$
\Delta \bar{m}^{a}=\frac{1}{k n} \sum_{1}^{k n} \Delta m^{a}[\mathrm{mg}],
$$


where: $\Delta m_{1}$ - mass wear during the first test (the first one of the five following tests begins of using the new sharp edge) after 15 shaft revolutions [mg], $\Delta m^{a}$ - mass wear during other tests (except the first one), i.e., loss of mass in the result of dominant abrasive wear after ending of the blade (edge) crumbling [mg], $n$ - number of tested blades, $k=p-1, p-$ number of tests.

As during the first test with use of sharp edge both abrasive wear and brittle fracture takes place, the average loss of mass only in the result of blade crumbling is determined form the following relationship:

$$
\Delta \bar{m}^{F}=\Delta \bar{m}_{1}-\Delta \bar{m}^{a}(\mathrm{mg})
$$

and the volumetric wear only in the result of abrasion is determined form the following relationship:

$$
\Delta \bar{V}_{a}=\frac{\Delta \bar{m}^{a}}{\rho}\left[\mathrm{mm}^{3}\right]
$$

Average volumetric wear only in the case of the blade crumbling is calculated from the following formula:

$$
\Delta \bar{V}_{F}=\frac{\Delta \bar{m}^{F}}{\rho}\left[\mathrm{mm}^{3}\right],
$$

where $\rho$ is density $\left(\mathrm{mg} \mathrm{mm}^{-3}\right)$.

Abrasion resistance:

$$
A R=\frac{15}{\Delta \bar{m}^{a}}\left[\mathrm{rev} \mathrm{mg}^{-1}\right]
$$

Volumetric abrasion resistance:

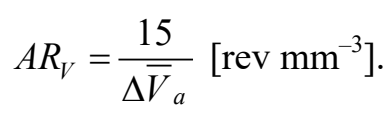

Fracture resistance:

$$
F R=\frac{15}{\Delta \bar{m}^{F}}\left[\mathrm{rev} \mathrm{mg}{ }^{-1}\right]
$$

Volumetric fracture resistance:

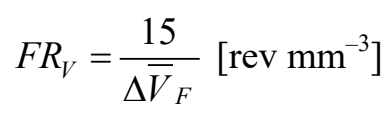




\section{ASSESSMENT OF SINTERED CARBIDES RESISTANCE TO BRITTLE FRACTURE AND ABRASIVE WEAR}

There are many types of sintered carbides used for inserts of cutting picks. One of the criterion of their division is the grain size of tungsten carbide $\mathrm{WC}$, according to which sintered carbides are divided into (ISO 4499-2, 2008; Ortner et al., 2014): nanograined $(<0.2 \mu \mathrm{m})$, ultra-fine $(0.2 \div 0.5 \mu \mathrm{m})$, sub-micron $(0.5 \div 0.8 \mu \mathrm{m})$, fine-grained $(0.8 \div 1.3 \mu \mathrm{m})$, medium-grained $(1.3 \div 2.5 \mu \mathrm{m})$, coarse-grained $(2.5 \div 6.0 \mu \mathrm{m})$, as well as super coarse-grained $(>6.0 \mu \mathrm{m})$ according to the size of tungsten carbide (WC). Depending on the application, the sintered carbides can be divided into the following grades (according to $\mathrm{PN}-88 / \mathrm{H}-89500$ ): $\mathrm{B}, \mathrm{G}, \mathrm{H}, \mathrm{S}, \mathrm{U}$ and $\mathrm{HF}$, but depending on the chemical composition there can be the following carbides: $\mathrm{WC}+\mathrm{Co}$ and $\mathrm{WC}+$ $(\mathrm{Ti}, \mathrm{Ta}, \mathrm{Nb}) \mathrm{C}+\mathrm{Co}$.

Table 1. Chemical composition and mechanical properties of sintered carbides given by the manufacturer (Baildonit 2004)

\begin{tabular}{|l|c|c|c|c|c|c|c|}
\hline \multirow{2}{*}{$\begin{array}{c}\text { Sample } \\
\text { marking }\end{array}$} & \multicolumn{2}{|c|}{ Chemical composition (wt. \%) } & \multirow{2}{*}{$\begin{array}{c}\text { Density } \\
{\left[\mathrm{g} \mathrm{cm}^{-3}\right]}\end{array}$} & $\begin{array}{c}\text { Young's } \\
\text { modulus } \\
{[\mathrm{GPa}]}\end{array}$ & $\begin{array}{c}\text { Hardness } \\
\text { HV30 }\end{array}$ & $\begin{array}{c}\text { WC grain } \\
\text { size } \\
{[\mu \mathrm{m}]}\end{array}$ \\
\hline B2 & 91 & - & 9 & 14.60 & 590 & 1250 & 3 \\
\hline B23G & 90.5 & - & 9.5 & 14.60 & 580 & 1050 & $6-10$ \\
\hline G10 & 94 & - & 6 & 14.90 & 630 & 1430 & 3 \\
\hline G30 & 85 & - & 15 & 14.00 & 540 & 1150 & 2 \\
\hline H10 & 94 & - & 6 & 14.90 & 640 & 1600 & $1-2$ \\
\hline S30 & 87 & 5 & 8 & 13.40 & 520 & 1450 & $2-3$ \\
\hline
\end{tabular}

Table 2. Results from tests at normal force,

$F_{n}=1000 \mathrm{~N}$ and each consecutive test duration, $i=15 \mathrm{rev}$.

\begin{tabular}{|c|c|c|c|c|c|c|c|}
\hline \multirow{2}{*}{$\begin{array}{l}\text { Sample } \\
\text { marking }\end{array}$} & \multicolumn{7}{|c|}{ Test results: mean value / standard deviation } \\
\hline & $\begin{array}{c}\Delta \bar{m}_{1} \\
{[\mathrm{mg}]}\end{array}$ & $\begin{array}{l}\Delta \bar{m}^{a} \\
{[\mathrm{mg}]}\end{array}$ & $\begin{array}{l}\Delta \bar{m}^{F} \\
{[\mathrm{mg}]}\end{array}$ & $\begin{array}{c}\Delta \bar{V}_{a} \\
{\left[\mathrm{~mm}^{3}\right]}\end{array}$ & $\begin{array}{c}\Delta \bar{V}_{F} \\
{\left[\mathrm{~mm}^{3}\right]}\end{array}$ & 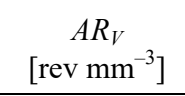 & $\begin{array}{c}F R_{V} \\
{\left[\mathrm{rev} \mathrm{\textrm {mm } ^ { - 3 }}\right]}\end{array}$ \\
\hline B2 & $0.66 / 0.080$ & $0.30 / 0.032$ & $0.36 / 0.086$ & $0.02 / 0.003$ & $0.02 / 0.006$ & $720.0 / 48.0$ & $609.7 / 40.8$ \\
\hline $\mathrm{B} 23 \mathrm{G}$ & $1.07 / 0.044$ & $0.72 / 0.040$ & $0.35 / 0.060$ & $0.05 / 0.006$ & $0.02 / 0.005$ & $305.9 / 20.5$ & $624.5 / 25.6$ \\
\hline G10 & $0.79 / 0.048$ & $0.26 / 0.019$ & $0.54 / 0.052$ & $0.02 / 0.002$ & $0.04 / 0.005$ & $873.6 / 58.3$ & $415.8 / 27.8$ \\
\hline G30 & $0.75 / 0.016$ & $0.39 / 0.027$ & $0.37 / 0.031$ & $0.03 / 0.003$ & $0.03 / 0.003$ & $541.3 / 36.1$ & $573.6 / 38.3$ \\
\hline $\mathrm{H} 10$ & $1.40 / 0.064$ & $0.14 / 0.027$ & $1.25 / 0.069$ & $0.01 / 0.002$ & $0.08 / 0.010$ & $1548.8 / 103.3$ & 177.1/11.9 \\
\hline $\mathrm{S} 30$ & $0.67 / 0.024$ & $0.24 / 0.032$ & $0.43 / 0.040$ & $0.02 / 0.003$ & $0.03 / 0.004$ & $846.3 / 56.5$ & $468.4 / 11.6$ \\
\hline
\end{tabular}


The fracture and abrasion resistance tests were carried out on the sintered carbides samples of fine, medium, coarse and super coarse granulation. Chemical composition with mechanical properties and grain size of the tested sintered carbides samples are presented in Table 1. The results of tests of abrasive wear and edge fracture of the selected sintered carbides are presented in Table 2.

Based on the results, the sintered carbides were classified regarding their resistance to abrasive wear (Fig. 6). Sintered carbides are ranked in order from the most abrasion wear resistant to the least resistant taking into account volumetric abrasion

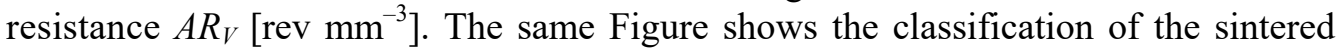
carbides for their resistance to brittle fracture based on volumetric fracture resistance $F R_{V}\left(\right.$ rev $\left.\mathrm{mm}^{-3}\right)$. The presented data shows that the increase in resistance to abrasive wear is accompanied by a decrease in the resistance to brittle fracture. This is due to the size of the tungsten carbide grains and the cobalt content.

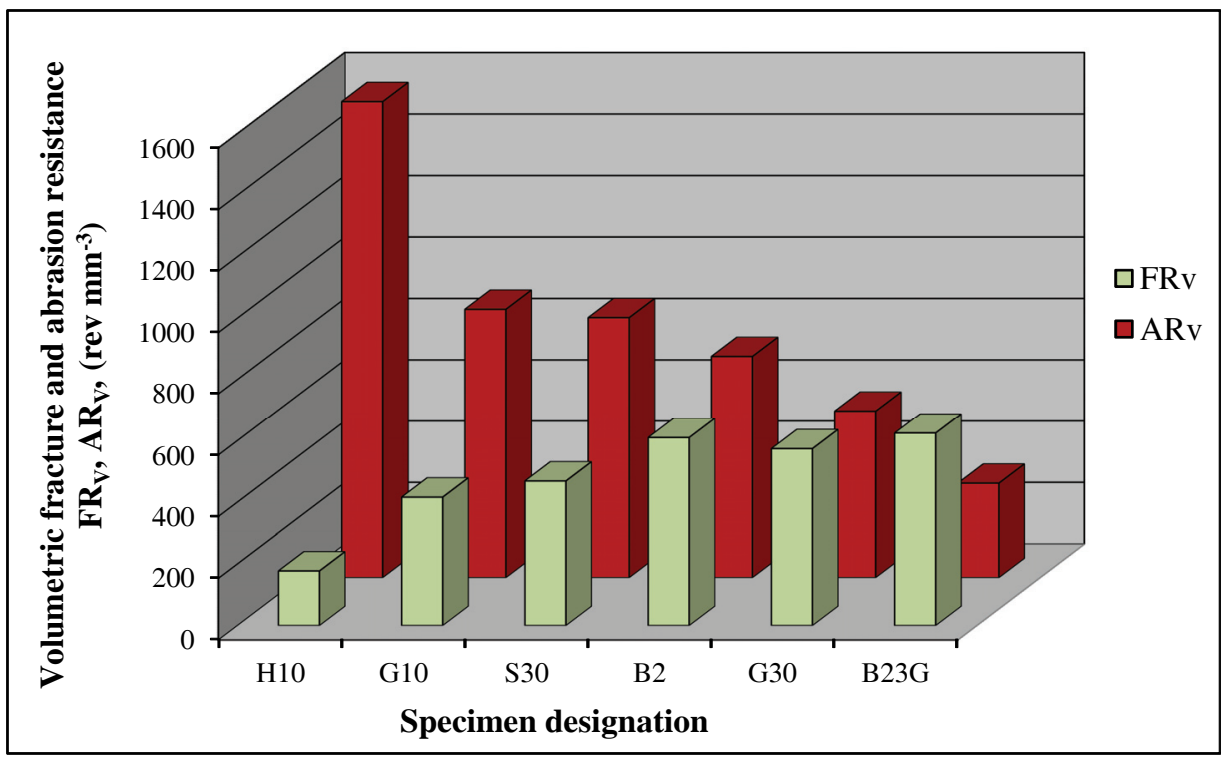

Fig. 6. Ranking of all tested sintered carbides according to their resistance to abrasive wear $A R_{V}$ and resistance to edge fracture $F R_{V}$

\section{METALLOGRAPHIC EXAMINATIONS OF SINTERED CARBIDES}

A microstructure of the metallographic micro cross-sections in the scanning electron microscope Zeiss Supra 35, at the accelerating voltage 15-20 kV and maximum magnification $50000 \times$ was also analyzed. A secondary electrons (SE) detector and a backscattered electrons (BSE) detector were used to obtain the microstructure images aiding 
for better distinguishing the changes in the phase composition of the analyzed area. The analysis of obtained images showed that the material of tested samples is characterized by a morphology typical for sintered carbides with homogeneous carbide phase. For example, the dark areas shown in the pictures (Figs. 7 and 8) correspond to the cobalt (Co) matrix, while the light color indicates for the tungsten carbide (WC) phase.
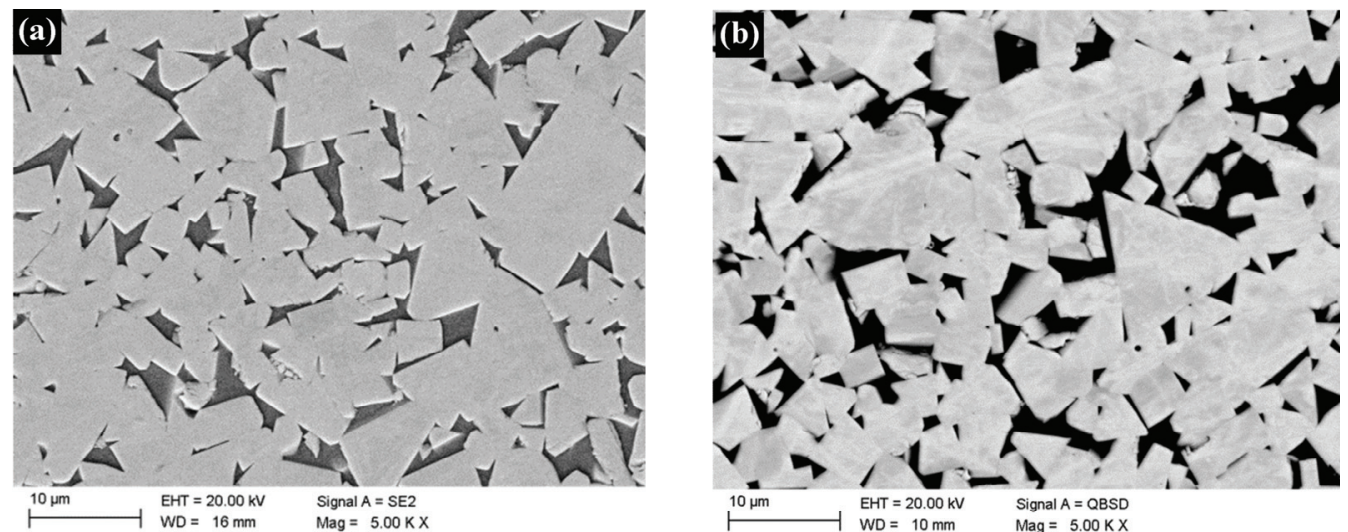

Fig. 7. SEM micrographs of sintered carbides B23G, Magn. 5000×: (a) SE detector, (b) BSE detector. Bright areas correspond to WC, while dark areas correspond to the Co based binder phase
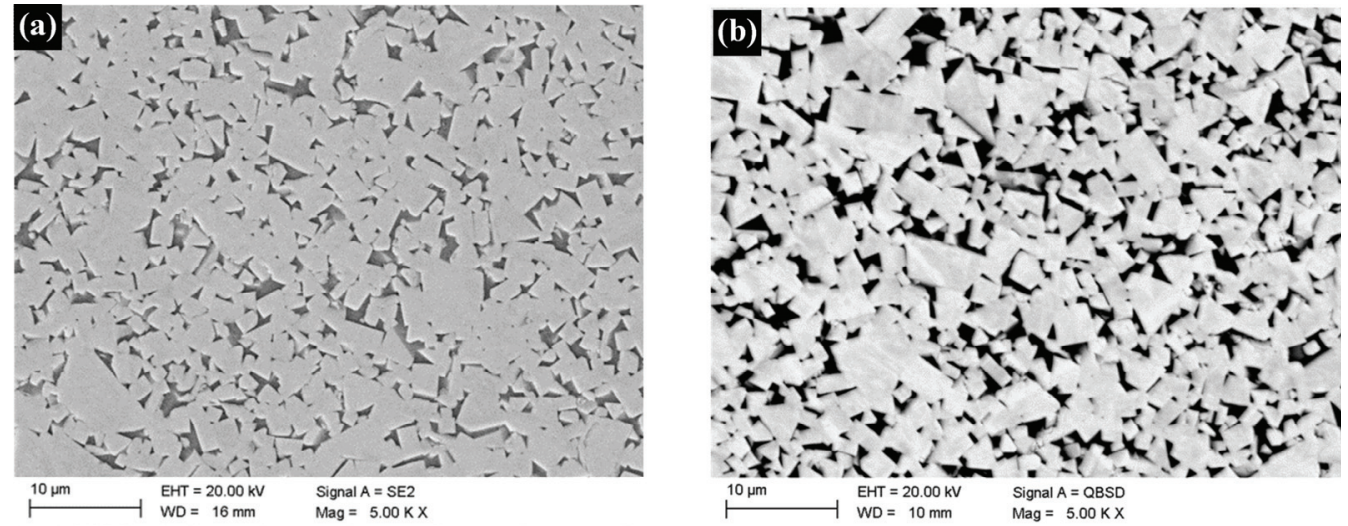

Fig. 8. SEM micrographs of sintered carbides B2, Magn. 5000×: (a) SE detector; (b) BSE detector. Bright areas correspond to $\mathrm{WC}$, while dark areas correspond to the Co based binder phase

A spectral analysis of the microstructure of micro-sections of the tested specimens was performed using EDAX's TRIDENT XM4 system, with an EDS (Energy Dispersive Spectroscopy) X-ray scattered radiation energy spectrometer. Quantitative and qualitative chemical composition was determined using this method in the selected 
points and areas of the tested materials. Examples of SEM micrographs and EDS spectrum of sintered carbides B23G and B2 are presented in Figs. 9 and 10. The aim of this part of the study was to verify the determination of the tested sintered carbides' grades.

Chemical composition of the tested sintered carbides is presented in Table 3. According to the information provided by the manufacturer of the tested sintered carbides (Table 1), the cobalt mass fraction (Co) should be as follows for the following grades: B2 - approx. 9\%, B23G - approx. 9.5\%, G10 - approx. 6\%, G30 - approx. 15\%, H10 - approx. $6 \%$, S30 - approx. 8\%. The obtained results of chemical composition (Table 3) indicate slightly different cobalt fraction in the matrix of the tested carbides. However, due to the nature of the energy-dispersive X-ray spectroscopy method (EDS), the results can be considered as being in line with expectations. Content of other alloying elements and admixtures was beyond the detection threshold of the method.
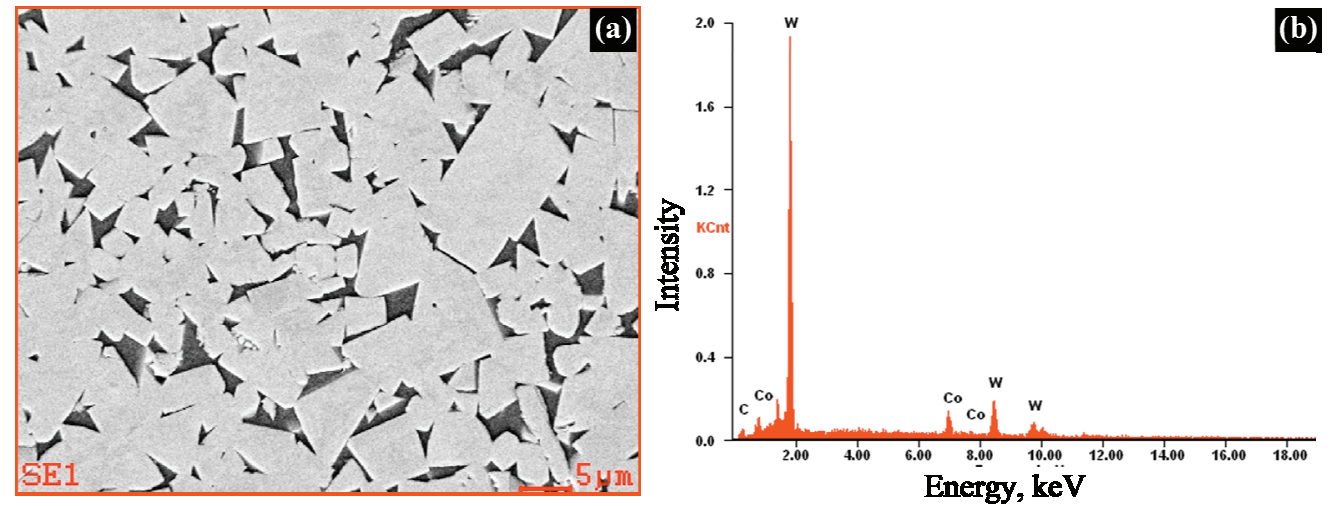

Fig. 9. (a) SEM micrographs of sintered carbides B23G (detector SE),

(b) EDS spectrum according to figure (a)
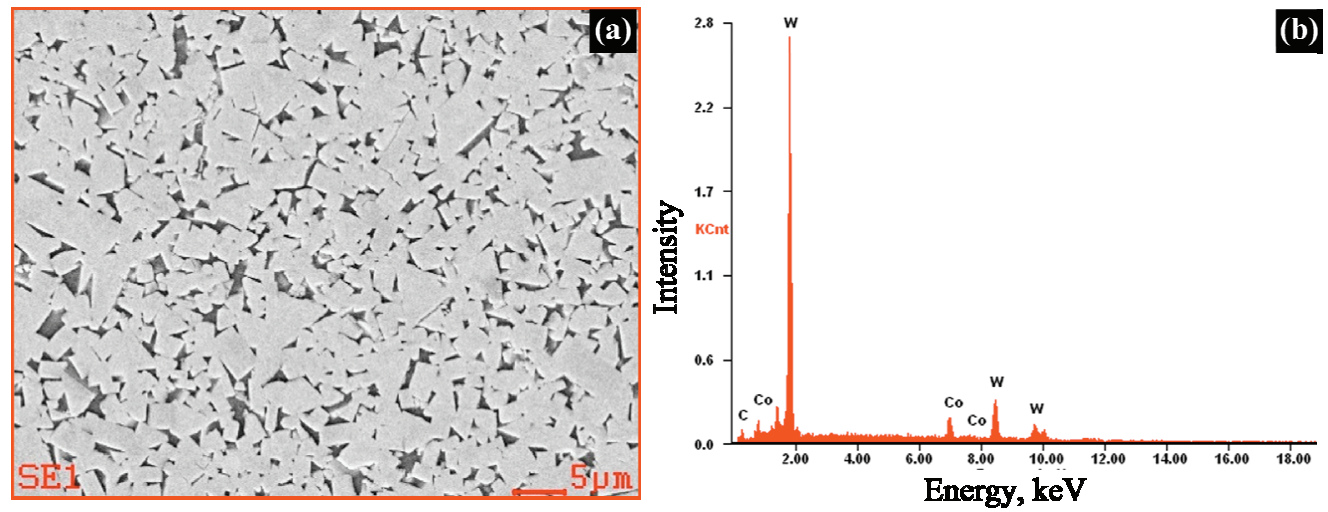

Fig. 10. (a) SEM micrographs of sintered carbides B2 (detector SE),

(b) EDS spectrum according to figure (a) 
Table 3. Chemical composition of tested sintered carbides

\begin{tabular}{|l|c|c|c|c|c|}
\hline \multirow{2}{*}{$\begin{array}{c}\text { Sample } \\
\text { marking }\end{array}$} & C & Co & Ti & W & Total \\
\cline { 2 - 6 } & \multicolumn{5}{|c|}{ Chemical composition [wt. \%] } \\
\hline B2 & 7.51 & 8.94 & - & 83.55 & 100.00 \\
\hline B23G & 7.35 & 9.31 & - & 83.34 & 100.00 \\
\hline G10 & 12.40 & 5.98 & - & 81.62 & 100.00 \\
\hline G30 & 11.59 & 14.87 & - & 73.54 & 100.00 \\
\hline H10 & 12.41 & 5.94 & - & 81.65 & 100.00 \\
\hline S30 & 10.41 & 7.97 & 4.91 & 76.71 & 100.00 \\
\hline
\end{tabular}

\section{QUALITY OF SINTERED CARBIDES INSERTS EMBEDMENT}

Quality of sintered carbides inserts embedment in pick body is determined by filling the solder gap. Surface area of the solder, voids and solder gap can be analysed based on the stereoscopic microscope measurements. Metallographic microsections of connection between the pick body, solder and sintered carbides inserts should be made on perpendicular sections along the symmetry axis were averaged.

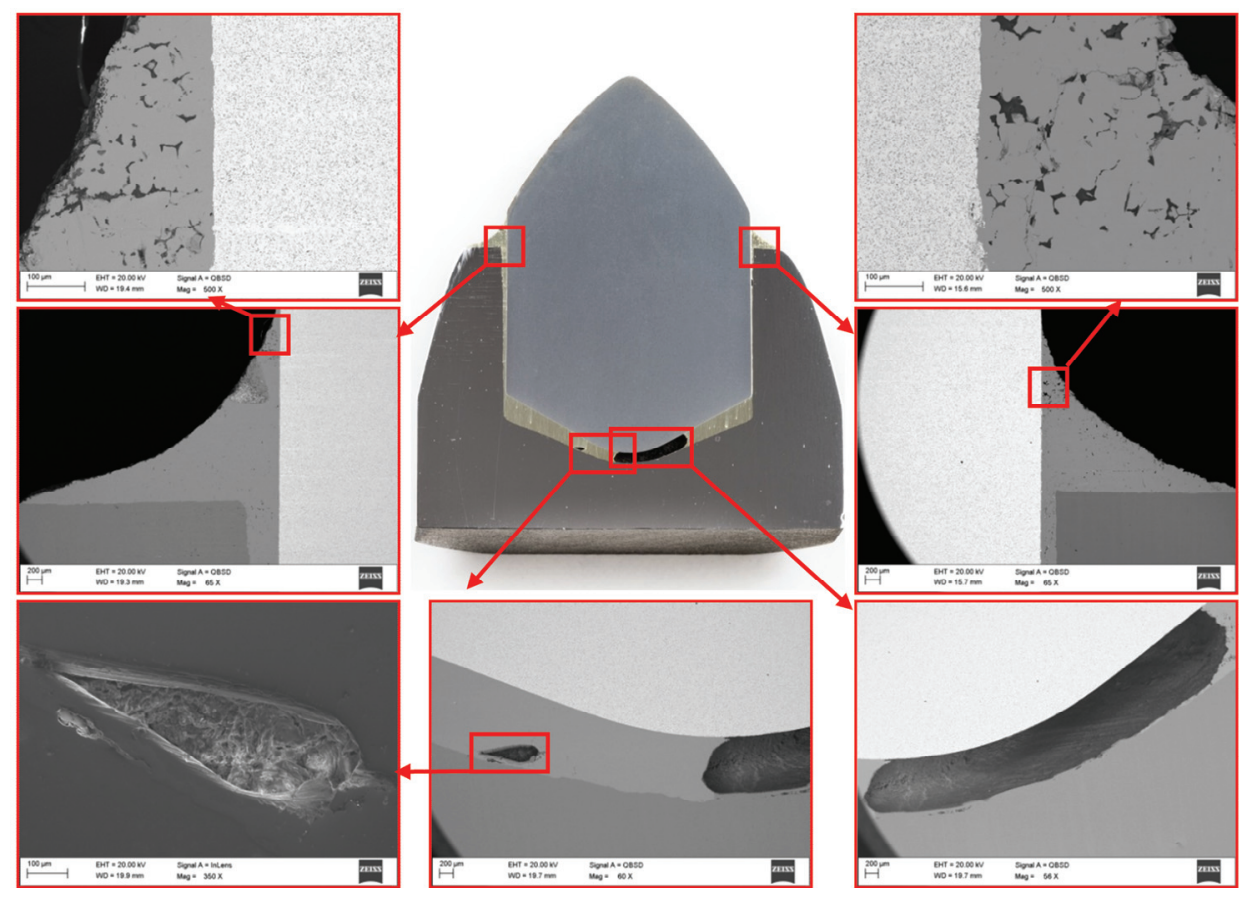

Fig. 11. SEM photos of metallographic microsections covering the connection between the sintered carbides insert and the pick body 
Figure 11 presents the sample SEM photos of metallographic microsections covering the connection between the sintered carbides insert and the pick body. The closeups show the material defects of the solder and inaccuracy of the insert embedment in the body. The insert is mounted asymmetrically and non-axially. There are numerous voids due to the lack of solder and heterogeneous solder structure around the insert on the outer surface of the body. Further analysis by the energy dispersive spectroscopy EDS shows the presence of numerous chemical compounds that fill microcracks, which can be the beginning of the solder structure destruction due to dynamic loads (material fatigue).

\section{CONCLUSIONS}

A relationship between a sintered carbide grades and fracture and abrasion resistance of the tested specimens was found based on the tests carried out. The obtained results were used to compare the tested sintered carbide grades in terms of their fracture and abrasion resistance. The tests carried out show that $\mathrm{B} 23 \mathrm{G}$ carbides have the highest fracture resistance among the tested sintered carbides, while H10 carbides have the lowest resistance. H10 carbides have the highest abrasion resistance, while B23G have the lowest resistance (Fig. 6). The abrasive wear of a relatively hard sample results in less weight loss.

A correlation between the size of carbide grains and the intensity of wear was also found, which is based on an increase in the resistance to abrasive wear of carbides with smaller grains.

It was found based on metallographic observations of micro-sections made in a scanning electron microscope that the investigated grades of sintered carbides are characterized by a coherent structure and uniformly distributed hard melting carbides in a cobalt matrix. The structure of sintered carbides (Figs. 7 and 8) is in accordance with the carbide particle size specified by the manufacturer (Table 1).

An analysis of chemical composition in micro-areas of the surface of the tested samples, using the EDS X-ray radiation energy spectrometry method, showed that, respectively, $\mathrm{C}, \mathrm{W}, \mathrm{Co}$ are present in the samples of sintered carbides and also $\mathrm{Ti}$ in the sample of the grade S30 sintered carbide. The obtained results of chemical composition measurements (Table 3) indicate slightly different content of chemical elements in the tested carbides than this given by the manufacturer (Table 1). However, due to the nature of the measurement method (EDS), the results obtained can be considered as being in line with expectations.

\section{ACKNOWLEDGEMENTS}

The publication was partially financed by statutory grant from Faculty of Mining, Safety Engineering and Industrial Automation, Silesian University of Technology. 


\section{REFERENCES}

ASTM Designation G65-04, 2010, Standard test method for measuring abrasion using the dry sand/rubber wheel apparatus.

Baildonit, 2004, Sintered carbide inserts for mining tools - selected properties, Katowice, Węgliki Spiekane BAILDONIT.

ISO 4499-2:2008 (E), Hardmetals - Metallographic determination of microstructure. Part 2: Measurement of WC grain size.

MANN R., 2014, The effect of geometrical characteristics of conical picks on energy consumption of cutting with roadheaders, Publishing House of Silesian University of Technology, Gliwice.

ORTNER H.M., ETTMAYER P., KOLASKA H., 2014, The history of the technological progress of hardmetals, Int. J. Refract. Met. Hard Mater., 44, 148-159.

ŚCIESZKA S.F., GRZEGORZEK W., ŻOŁNIERZ M., 2013, Tribotesting system for hardmetals mechanical characterization, Int. J. Refract. Met. Hard. Mater., 41, 470-482.

ŚCIESZKA S.F., GRZEGORZEK W., ŻOŁNIERZ M., WULCZYŃSKI J., 2015, Method and device for testing the fracture toughness and abrasive wear of advanced construction and tool materials, Institute for Sustainable Technologies, Radom, 163-179. 